\title{
Prospects for Cooperation in Science, Technology and Innovation among the BRICS Members
}

\author{
M. Kahn
}

Michael Kahn - Professor Extraordinaire, Stellenbosch University; Director, Research and Innovation Associates; Private Bag X1, Matieland 7602, Western Cape, South Africa; E-mail: mjkahn@sun.ac.za

The establishment of the New Development Bank by the BRICS group of Brazil, Russia, India, China and South Africa signalled the maturing of the financial relationships among the partners of the "club." These relationships have acquired a heightened profile through the Cape Town Declaration whereby the BRICS Ministers of Science and Technology committed to cooperation. The declaration raises interesting questions, inter alia the status of intraBRICS cooperation on science, technology and innovation (STI), the rationale for the choice of the specific fields of cooperation, and the countries'strengths in these fields. How do these fields align with each country's domestic strategy for STI? Which bilateral STI agreements are already in place, and what have they delivered? How does the Cape Town Declaration align or compromise the India-Brazil-South Africa (IBSA) process? Will the rising geopolitical tensions (Black Sea, China Sea) limit the scope of STI cooperation? The secondary objective of this article is to demonstrate why South Africa is important to the club. Addressing these questions requires a study of geopolitics, finance, trade and other modes of engagement, STI included. A convenient framework is a macro-level political, economic, social, technological, environmental and legal (PESTEL) analysis, with a more detailed look given to the "T," for which can be read STI. The analysis of other documents and economic, social and STI indicators, together with bibliometric data provide the empirical basis for the arguments. Together with the identification of national imperatives, this analysis allows the potential of the Cape Town Declaration to be assessed. Not only is South Africa the "Gateway to Africa," but the country also displays the highest level of intra-BRICS scientific cooperation.

Key words: BRICS; Cape Town Declaration; cooperation in science, technology and innovation; bibliometrics; South Africa; Gateway to Africa

\section{Introduction}

A little more than a decade ago Jim O’Neill, former chair of Goldman Sachs Asset Management, famously identified the BRIC grouping of Brazil, Russia, India and China as a significant economic bloc. Over that time, recession notwithstanding, the BRIC countries have grown in economic significance far beyond expectation. Then, in 2011 South Africa, already a member of the G20 and the major voice in Africa, joined the BRIC family, which duly morphed into the BRICS. O'Neill drily observed that South Africa had no place in the BRIC club given its modest size, and that by contrast Indonesia, Mexico or Turkey had stronger claims to join. The recent downturn in the fortunes of Brazil and Russia has since persuaded O'Neill to question the very idea of the BRIC core that in his view might wither down to "IC" alone. This suggests that it is timely to probe deeper into some of the underlying trends that characterize the relationships among the five BRICS countries. That is a narrow economic view.

The primary objective of this paper is therefore to consider a somewhat neglected aspect of these relationships by investigating the rhetoric and reality concerning intra-BRICS cooperation in science, technology and innovation (STI). This arena of engagement has acquired a 
heightened profile through the 10 February 2014 Cape Town Declaration whereby the BRICS ministers of science and technology committed to a programme of STI cooperation.

The secondary objective of this article is to show why O'Neill is incorrect in his assertion that South Africa does not matter. To provide such rebuttal requires a study of geopolitics, finance, trade and other modes of engagement, STI included.

The Cape Town Declaration acknowledges the lead role of science and technology for long-term development and proposes specific responsibilities for each country. The declaration should have been ratified at the BRICS summit of July 2014 held in Fortaleza, Brazil, but that meeting was dominated by the launch of the New Development Bank (with a capitalization of $\$ 100$ billion) and Contingent Reserve Allocation (also \$100 billion) [Ortiz, 2014]. The Cape Town Declaration was ratified in March 2015 at a meeting of the BRICS science and technology ministers in Brasilia.

Science, by virtue of its claimed universality, displays a veneer of political neutrality, and has a long history before and since the Enlightenment of acting as a channel for dialogue among city-states and nations. Science is an intimate component of soft diplomacy, an art best illustrated by the table tennis tournaments of the 1975 Nixon-Zedong rapprochement, and most recently in the European Union Horizon 2020 call for studies on European cultural and science diplomacy to exploit "the potential of culture and science in the EU's external relations" [European Commission, 2014].

Technology and technology transfer are quite different, for reasons of competition and security. Business innovation is intimately linked with economic competition and spreads by a variety of mechanisms through linkages among firms. It manifests itself through imitation, reverse engineering (theft by any other name), adaptation, creativity and secrecy. In the security domain, secrecy is paramount and sharing is restricted and prosecutable. It is of more than academic interest to unpack the potential of the Cape Town Declaration, and to separate the rhetoric from the reality.

The stellar economic growth of the BRICS in the first decade of the 21 st century has been accompanied by a rapid increase in their contribution to the global stock of knowledge. More precisely, between 2002 and 2007 Brazil, China and India each doubled their respective gross expenditure on research and development (GERD), with their share of global GERD rising from $17 \%$ to $24 \%$. Indeed, China's share of global GERD is now on par with its share of world gross domestic product (GDP), and between 2004 and 2010 China's share of world scientific publications doubled. This growth gives notice of a major shift in the locus of scientific publishing signified by the new triad of the United States, Europe and Asia, with Asia expected to become the dominant scientific continent in the medium term [Hollanders and Soete, 2010; Meyer and Nascimento, 2014]. As will be shown below, international co-publication has also risen steeply over this period.

International scientific collaboration is part of the new globalization of knowledge, and the Cape Town Declaration seeks to harness this momentum to the benefit of the BRICS. The declaration proposes country specializations as follows: Brazil - climate change and disaster mitigation; Russia - water resources and pollution treatment for Russia; India - geospatial technology and applications; China - new and renewable energy, and energy efficiency; and South Africa - astronomy.

To understand the viability of BRICS cooperation in STI it is necessary to answer a number of questions. What is the present state of STI cooperation among the BRICS members? What is the explanation for the selection of the five fields of interest? Furthermore, do these fields align with country domestic strategies for STI? This allows an assessment of country-tocountry interactions: which bilateral STI agreements are already in place, and what have they 
delivered? How does the Cape Town Declaration align or compromise the collaboration of the India-Brazil-South Africa (IBSA) Dialogue Forum? Will the rising geopolitical tensions (Black Sea, China Sea) limit the scope of STI cooperation? Underscoring these questions and answers is the role, if not the legitimacy of the smallest of the BRICS members, South Africa.

A convenient organizing framework against which these questions may be assessed is a political, economic, social, technological, environmental and legal (PESTEL) analysis. Space considerations dictate that this focus on the macro level, with a more detailed look given to "technological" factors, or STI. Together with bibliometric data, the analysis of other documents and economic, social and STI indicators will provide the empirical basis. This article is organized into sections as follows. Following the introduction, the next section addresses the political, economic, social, environmental and legal dimensions. The technological features are covered in the next section that examines the state of STI in each of the BRICS countries. This is followed by an analysis of scientific activity using publication counts as a proxy measure. This also allows for an assessment of the level of STI cooperation among the BRICS members. Together with the identification of national imperatives, this analysis allows the potential of the Cape Town Declaration to be assessed. The next section places STI cooperation in the much larger context of geopolitics: the Russia-China energy accord, India's newly assertive foreign policy, South Africa as the "Gateway to Africa" and Brazil's role in Africa as commodity exploiter and entrepreneur. The final section returns to O'Neill's assertions and their rebuttal.

\section{Environmental Scan - PESTEL Analysis}

PESTEL analysis, sometimes referred to as PESTLE, is a tool that has evolved to inform strategic management, with first environmental and then legal factors added to the earlier political, economic, social and technological (PEST) analysis. A PESTEL analysis seeks to delineate the macro-environment within which strategic choices are to be made, and is often followed with a detailed strengths, weaknesses, opportunities and threats (SWOT) analysis.

The PESTEL analysis that follows is necessarily a bird's eye view of a massive terrain of study. It represents but a first pass at analyzing what is a complex and contested landscape. This analysis is grounded in the empirical evidence of Table 1, and commences with the politicolegal factors.

Table 1: PESTEL Indicators (2012 or nearest)

\begin{tabular}{|l|c|c|c|c|c|}
\hline & Brazil & Russia & India & China & South Africa \\
\hline Global Competitiveness Index $^{\mathrm{a}}$ & 56 & 64 & 60 & 29 & 53 \\
\hline Basic requirements & 79 & 47 & 96 & 31 & 95 \\
\hline Efficiency enhancers & 44 & 51 & 42 & 31 & 34 \\
\hline Innovation/Sophistication & 46 & 99 & 41 & 34 & 37 \\
\hline Institutions & 80 & 121 & 72 & 47 & 41 \\
\hline Financial market development & 50 & 121 & 19 & 54 & 3 \\
\hline Defence expenditure/GDP \% & 1.5 & 4.0 & 2.5 & 2.0 & 1.2 \\
\hline GERD/GDP \% & 1.2 & 1.12 & 0.88 & 1.98 & 0.76 \\
\hline BERD/GERD \% & 45 & 26 & 30 & 74 & 47 \\
\hline Researchers/1,000 employed & 1.4 & 6.2 & $0.4^{\mathrm{b}}$ & 1.8 & 1.6 \\
\hline Web of Science/million & 180 & 191 & 38 & 136 & 181 \\
\hline
\end{tabular}




\begin{tabular}{|l|c|c|c|c|c|}
\hline \multicolumn{1}{|c|}{$\begin{array}{c}\text { Main fields of publication } \\
\text { (Web of Science) }\end{array}$} & $\begin{array}{c}\text { Clinical } \\
\text { medicine, } \\
\text { biology, } \\
\text { biomedical }\end{array}$ & $\begin{array}{c}\text { Physics, } \\
\text { chemistry, } \\
\text { engineering }\end{array}$ & $\begin{array}{c}\text { Chemistry, } \\
\text { clinical } \\
\text { medicine, } \\
\text { engineering }\end{array}$ & $\begin{array}{c}\text { Chemistry, } \\
\text { Engineering, } \\
\text { physics }\end{array}$ & $\begin{array}{c}\text { Clinical } \\
\text { medicine, } \\
\text { biology, } \\
\text { chemistry }\end{array}$ \\
\hline USPTO/m & 1.3 & 2.4 & 1.4 & 4.0 & 3.1 \\
\hline Plant cultivars in force/million & 8.6 & 29.3 & n.a. & 2.6 & 48 \\
\hline Global Innovation Index & 67 & 52 & 87 & 46 & 51 \\
\hline Gini coefficient & 51.9 & 42.0 & 36.8 & 47.3 & 63.1 \\
\hline Decile 10/Decile 1 & 54 & 7 & 9 & 18 & 43 \\
\hline Human Development Index & 85 & 55 & 136 & 101 & 121 \\
\hline Annual $\mathrm{CO}_{2}$ tonnes/capita & 2.15 & 12.18 & 1.64 & 6.18 & 9.18 \\
\hline
\end{tabular}

Notes: GDP = gross domestic product; GERD = gross expenditure on research and development; USPTO $=$ United States Patent and Trademark Office, $\mathrm{CO}_{2}=$ carbon dioxide .

All data are for 2012 except for the Global Competitive Index, which draws on 2013-14 data.

${ }^{a}$ The Global Competitiveness Index uses indicators accessed from multiple sources and comprises 12 pillars in three groups: basic requirements (institutions, infrastructure, macroeconomic environment, health and primary education); efficiency enhancers (higher education and training, goods and labour market efficiency, financial market development, market size, technological readiness); and innovation and sophistication (business sophistication and innovation). Values for institutions (1) and financial market development (8) are shown. The various indicators are a mix of quantitative and qualitative.

${ }^{\mathrm{b}}$ Author's estimate.

Sources: CIA Factbook; World Bank; World Economic Forum; Organisation for Economic Cooperation and Development main science and technology indicators; Red de Indicadores de Ciencia y Tecnología; Web of Science; U.S. Patent and Trademark Office; Union of Plant Varieties, INSEAD.

A commonality of the BRICS countries is that they have all experienced significant political ruptures in the last 30 years. They share a history of authoritarian rule, in some cases under direct military control, in others via an overarching ruling elite, and to this day display elements of what Douglass North, John Wallis and Barry Weingast [2009] refer as "mature natural states." Politically (and legally) speaking the BRICS countries, China excepted, are multi-party "democracies," but they have not transitioned into fully fledged open access societies. Their relatively low scores on the Global Competitiveness Index (GCI) measurement of institutions attest to this assertion. Significant ruptures were experienced in Brazil, Russia, India and South Africa from 1991 to 1994, partly as a result of the ending of the Cold War, the deepening of globalization and the spread of the Washington Consensus. Following the 1986 move to democracy, Brazil adopted a programme of structural adjustment under the Plano Real in 1994. This brought inflation under control, thereby stabilizing the currency. Privatization of state assets formed part of the programme mix. After the collapse of the Soviet Union, Russia underwent radical economic transformation through the rapid adoption of free market economics and the privatization of state assets. India, under the guidance of Manmohan Singh began to deconstruct the "licence Raj," but still maintained a strong protectionist stance against foreign penetration. China, following the land and agriculture reforms over 1949 to the 1960s, commenced a second "Long March" in 1978, this one down the capitalist road [Studwell, 2013]. South Africa, maintaining the thrust of the outgoing minority government, accelerated a neoliberal agenda as the country re-entered world markets. To a large extent it maintained the mix of state ownership of the commanding heights, with a vibrant private sector that rapidly spawned new transnational corporations. Having gained political rights, the African majority began a second long walk toward economic freedom. 
These ruptures had major internal and external impacts, with the rise of China as the new factory of the world becoming a decisive factor in global trade and finance. The inexorable growth of China's economic might has moved it to rank second in size after the United States. All things being equal, China will be the largest economy in the world within a decade. This shift from West to East, with India now moving up to rank third manifests the new global order of multipolarity. After the brief period during which the United States was the sole superpower, there are now numerous centres of power: the U.S., the European Union, Japan, Russia, China, India, Brazil and South Africa. Indonesia, Mexico and Turkey stand alongside, waiting their turn to influence regional events. India and China are engaged in a space race, and in common with Japan are also expanding their military, especially their naval capabilities. In this multipolar world new political alliances are being formed, and dormant tensions are igniting. The form that a new equilibrium will take is elusive. Pax Americana is yielding to pax fragile, with some commentators even speaking of Cold War II [Trenin, 2014].

During the period of military rule Brazilian industry deepened and broadened even as its current account deficit worsened. Examples of this diversification were sugar-to-ethanol production, offshore oil extraction, the opening of the highland cerrado to large-scale crop farming, aeronautical engineering and the creation of new overseas markets to be exploited by its construction companies. The worsening financial situation then persuaded the military to relinquish power to civilian control and to allow a democratic process to unfold. Brazil was able to enter the 1990s as a large-scale exporter of agricultural commodities and mineral ores, along with manufactured goods and services. It is noteworthy that Brazil's Africa-oriented foreign policy dates back to the time of the generals. In fact, when the Marxist MPLA government gained power in Angola in 1975, Brazil was the second country to recognize the new government. Brazil then used this political legitimacy to grow its trading footprint across Lusophone Africa and beyond.

In the 1990s the Russian government transferred many state mining, metal and energy enterprises to private control. Russia opened her economy to western capital and allowed their companies to grow and capture the consumer market. However, Russian companies have lagged behind as innovators so that this foreign dominance has continued [Kuznetsova, 2013]. The Russian economy is painfully dependent on the export of oil, gas and minerals, which together with the sanctions arising from the Ukraine crisis has caused severe financial problems. Russia maintains significant prowess in military and aerospace capability, spending 4\% of GDP on defence ( $\$ 100$ billion in purchasing power parity [PPP]), the highest proportion among the BRICS countries. Russia was of course a major actor in Africa during the Cold War, and these prior relationships continue into the present, enabling the new non-state actors of Russia to engage in infrastructure and mineral development in Africa.

India has been slower to embrace the challenges and opportunities of the multipolar world and globalization. India's politics are complicated by its vast ethnic diversity, vestiges of central planning, ongoing tension with Pakistan and nervousness regarding the intent of China with which it has previously engaged in open warfare. India is belatedly expanding its diplomatic footprint and its navy, with defence expenditure now at $2.5 \%$ of GDP (\$121 billion of PPP). Its private sector shows considerable ability to manage complex merger and acquisition deals, thereby making Tata, Mittal, Reliance and Infosys global brands. India's presence in Africa is growing slowly.

China is sui generis - the Communist Party rules; the free market creates prosperity. In Deng Xiaoping's words, “It doesn't matter whether a cat is white or black, as long as it catches mice." Hence state capitalism is embraced in an ever-increasing number of special economic zones. Joe Studwell [2013] argues that political freedoms are only loosely coupled with economic growth in China, so economic growth and outward expansion continue unabated. The 
Chinese government made an explicit decision in 2006 to reach out across the globe and it is now the largest source of foreign direct investment (FDI) into its bordering countries, and a major source for Africa.

China was the major promoter of South Africa's accession to the BRIC club. In return South Africa lends its political and moral standing to China's positions in international political forums, most recently denying the Dalai Lama a visa to attend a meeting of Nobel Laureates in Cape Town. This support is somewhat unexpected since in 1961 South Africa's ruling party turned to the Soviet Union for military assistance when it embarked upon armed struggle; China played a much smaller role in the anti-apartheid campaign than did the Soviet Union. Wielding economic might as a major creditor to western consumers, China is now also asserting itself diplomatically and militarily in pursuit of its territorial claims in the South China Sea. This explains its naval expansion, and defence spending of $2 \%$ of GDP ( 245 billion PPP).

As to the economic domain, the GDP statistics confirm O'Neill's original conjecture that size counts, with China having overtaken Japan to become the second largest economy after the United States. From an economic viewpoint the BRICS are composed of China plus the rest the "BRIS." China's relations with the BRIS are severely lopsided, with a trade balance very much oriented in China's favour, as mineral, energy and agricultural commodities flow eastward while manufactured goods and state-funded infrastructure projects ship in the opposite direction. Demand is influenced by the strength of domestic markets and purchasing power as reflected in per capita income. Russia scores low on the indicators most closely associated with free markets, and as Natalia Gorodnikova [2014] argues, it has proven difficult for innovative firms to emerge and prosper in Russia.

South Africa is arguably the major political player on the African continent. At home it is central to the Southern African Customs Union that includes Botswana, Lesotho, Namibia and Swaziland, and dominates the 15 countries in the Southern African Development Community. Further afield the country promoted both the forming of the New Partnership for Africa's Development (NEPAD), and the transformation of the moribund Organization of African Unity into the African Union, currently chaired by South Africa's Nkosasana Dlamini-Zuma. South Africa has deployed peacekeeping forces to South Sudan, the Central African Republic and the Democratic Republic of Congo, played a mediating role in the Great Lakes conflict resolution process, and acted as intermediary under the Mandela administration to bring Libya in from the cold. The extreme monopoly capitalism of the 1960-1990 period has since given way to more diverse ownership of equities (in the hands of foreign portfolio managers), and state pension and investment funds. Simultaneously its leading publicly listed companies have expanded across the Limpopo River in a second Great Trek, but this time of commercial brands, rather than cattle farmers. Many of these companies have secondary listings abroad and they derive up to half of their revenues globally.

The cement for the BRICS comes from a shared desire to rebalance global political power relations and institutions in the same way that global market forces have rebalanced economic power. BRICS members' internal and bilateral issues are another matter entirely, with care taken to refrain from public criticism of one another. For the present Russo-Sino relations are orderly, with a mammoth 30-year gas deal signed in 2014. Sino-India tensions are another matter entirely, with conflict a medium-term possibility, vide the close relationship blossoming between New Delhi and Tokyo. Brazil is quietly asserting its dominance of the South Atlantic, as evidenced in the planned purchase of French submarines and surface vessels, while South Africa tries to act as the African village policeman. Of the five BRICS members, South Africa has the longest continuous experience of business conducted according to "free market" norms and the rule of law (although the country excluded their African majority up to 1994). 
At this point it is appropriate to examine the data of the World Economic Forum (WEF) Global Competitiveness Report, whose index draws on a mix of quantitative and subjective indicators, the latter being gathered through the annual Executive Opinion Survey [Schwab, 2014]. Among the BRICS members, the Global Competitiveness Index (GCI) ranks China highest at position 29, and Russia lowest at 64 . This ordering is already evident in the institutions pillar for which South Africa is ranked highest in position 41, while Russia stands in position 121. South Africa retains its leading position for Financial Market Development, ranked third worldwide year on year. This gives the country important standing worldwide and particularly in Africa. To do business in Africa the place to start is the financial hub of South Africa. Until 2014 South Africa displayed the largest GDP in Africa, at which point Nigeria announced the results of its rebasing exercise that saw its GDP double and exceed South Africa's.

With regard to social factors, GCI's "Basic Requirements" pillars assess administrative capacity, health and primary education. Brazil, India and South Africa do poorly in addressing these basic requirements compared to Russia and China. The WEF measurements may be compared with the United Nations Development Programme's Human Development Index (HDI), the Gini coefficient and the new indicator $\mathrm{dX} / \mathrm{d} 1$. HDI is a proxy for human development based on life expectancy, educational attainment and income. It serves as an alternative to GDP per capita for measuring relative socioeconomic progress. South Africa's HDI slipped badly as a consequence of the HIV/AIDS epidemic that by 2005 had reduced life expectancy by nearly 10 years. With the introduction of large-scale state-sponsored antiretroviral therapies life expectancy had climbed to 61 years by 2012. Russia, with its stronger health and education systems ranks highest in the HDI among the BRICS countries. This average masks the major gender disparity in life expectancy, as females are outliving males by more than 10 years.

South Africa's Gini coefficient scores of 63.1 is among the highest in the world; at 36.8 India records the lowest Gini among the BRICS, although this places the country above the EU average of 30.6. Both Brazil and South Africa display high Gini coefficients for income, and have adopted extensive social welfare systems to mitigate absolute poverty. If these social benefits were included in the estimates of total household income, the Gini coefficient would be lower, though still unacceptably high.

An alternative measure of inequality is the Palma index that examines income distribution according to decile share [Cobham and Sumner, 2013]. A simplified Palma index may be calculated by comparing the ratio of the income accruing to decile 10 with that of decile 1 , termed here the $\mathrm{dX} / \mathrm{dI}$ ratio. The simplicity of the ratio arises from the fact that the necessary data is readily available on the CIA Factbook Library. Calculation of $\mathrm{dX} / \mathrm{dI}$ suggests that Brazil is less equal than the Gini suggests; conversely it shows that income disparities in Russia and India are relatively modest. As with other measures of inequality, even $\mathrm{dX} / \mathrm{dI}$ is a blunt instrument. The income accruing to the top $1 \%$ may be the most appropriate measure of income inequality, since this is the domain of billionaires, oligarchs and plutocrats (and media personalities).

It is worth briefly mentioning the environmental aspects of the PESTEL analysis before moving to the longer discussion concerning $S \& T$. The simplest comparable environmental indicator is carbon dioxide emission per capita. Russia, South Africa and China are large consumers of fossil fuels and among the highest carbon dioxide emitters in the world. Thanks to the availability of hydroelectricity, Brazil has a lower carbon footprint. The low emission value of India arises from its relative underdevelopment and low levels of industrialization. Specific mention must be made of toxic smog that pollutes many of China's large cities, with an estimated reduction of life expectancy by 5.5 years in the case of Beijing [Hook, 2013]. 


\section{Science, Technology and Innovation}

Traditions of western university and academy research go back more than a century in the five BRICS countries. All of the BRICS members experienced relatively late industrial revolutions and were able to benefit from imported technologies. Science was a strong component of the modernization and military agendas of the BRICS, with considerable technological transfers from the then Soviet Union to both China and India.

Today the BRICS countries display unique innovation systems, of different size, complexity and focus, with their own path dependencies [World Bank, 2010]. The Russian and Chinese academies of science teach and conduct research while their universities play smaller roles in research. South Africa's research councils and universities enjoy similar levels of research expenditure, with the latter solely responsible for awarding degrees. The world-renowned Indian Institutes of Technology and Tata Institute of Technology enrol students through a highly selective process, and stand alongside a massive university system complemented by public research institutions such as the Council of Scientific and Industrial Research (CSIR). Brazil's Embrapa is a world leader in agricultural research, as is medical research at the Oswaldo Cruz Foundation. The University of Sao Paulo is the academic research leader, standing at the pinnacle of the publicly funded state universities.

The present character and specializations of these innovation systems owe much to their earlier period of authoritarian, if not military rule, during which weapons production was a major consideration. Russia, China and India have nuclear weapons; Brazil foreswore the development of atomic weapons; and South Africa in 1994 uniquely dismantled its atomic arsenal. China, India and Russia have intercontinental ballistic missile and satellite launch capacity, with Russia and China having mastered manned space flight, and India intending to follow in 2016. The India Mars probe has placed her virtually on par with China. Brazilian Embraer has captured a niche in the market for mid-sized commuter aircraft, and the Brazilian Space Agency has launched its own rockets. For many years Brazil and South Africa have designed and built satellites that have been launched by other countries. Brazil and South Africa are cooperating in air-to-air missile technology, and India and Russia extensively share technology. South Africa still competes in light arms and artillery, as well as compact radar systems and military vehicles, based on the programmes developed following the 1977 UN arms embargo.

All have significant industrial capacity and high levels of self-sufficiency other than in the realm of consumer goods (enter China) and advanced technologies (enter the EU, U.S. and Japan). They possess advanced medical, scientific and technical skills and contribute to the global stock of knowledge. The private sector plays differing roles in these innovation systems according to the extent of state enterprise involvement and the residue of central planning. Among the BRICS members, the Global Innovation Index ranks China first in position 46, and India last in position 87 .

The BRICS members publish regularly updated STI strategies and have specialized agencies that gather and produce STI indicators. China, Russia and South Africa maintain strong engagement with the Science, Technology and Innovation directorate of the Organisation for Economic Co-operation and Development (OECD). As China's manufacturing capability has moved toward the technological frontier, its GERD has risen to reach $1.98 \%$ with an increasing proportion of this activity occurring in Chinese firms. In parallel, these firms have found it necessary to protect their intellectual property as Chinese brands proliferate globally. For China in particular, future growth is expected to spring from innovation driven development [Xinhua, 2013]. China's intensity of U.S. patent awards has also grown, and is the highest in the BRICS at 4.0 per million. This is a recent achievement, as is the rise in Chinese-authored articles recorded in the Web of Science database. Brazil, Russia and South Africa have similar publication 
intensity while South Africa stands second for U.S. patenting. India lags according to both of these key STI output indicators. The registration of plant cultivars is another important STI output; South Africa's intensity is nearly double that of Russia, and is far ahead of Brazil and China, reflecting the diversity of its agricultural base and associated exports.

Publication counts (cf. Table 2) must be prefaced with the usual caveats that bibliographic databases are incomplete, are biased toward the English language, and do not cover the social sciences and humanities in sufficient depth. This is particularly important for Brazil, China and Russia, which each have numerous national-language scientific publications not adequately represented in the Web of Science or Scopus until recently. Starting in 2006, the Web of Science moved to correct these biases and Brazil in particular saw a massive increase in the number of its national journals indexed in that database. The other four BRICS members enjoyed varying increases, with South Africa's coverage tripling. Notwithstanding these caveats, bibliometrics cannot function without using these databases. The BRICS show some similarities in their areas of concentration of scientific publications (cf. Table 1). The three leading fields of China and Russia are identical; Brazil and South Africa specialize in clinical medicine and biology. India is a mix of the two groupings with its emphasis on engineering. Wolfgang Glänzel [2001] suggests a typology according to which China and Russia display the "socialist" model; Brazil and South Africa are "western," while India is a mix of western and "Japanese." This typology is not cast in concrete and must change as economic dictates pull science along in new directions. The area of space science is also addressed, accounting for $10 \%$ of the totals for Russia and South Africa, and around 5\% for Brazil, China and India. These few STI output indicators cannot adequately capture the complexity of the wide range of activities that contribute to and arise from the process of innovation.

It is instructive to compare the different emphases that emerge from the Web of Science and Scopus. Table 2 provides total publication counts and the top three subject area concentrations on Scopus since 1995.

Table 2: Subject Area Specialization on Scopus, total publications post 1995

\begin{tabular}{|l|c|c|l|l|l|}
\hline & $\begin{array}{c}\text { Count, } \\
\text { 000s }\end{array}$ & $\begin{array}{c}\text { Count/ } \\
\text { Population } \\
\mathbf{0 0 0 , 0 0 0 s}\end{array}$ & $\begin{array}{c}\text { Subject Area 1, } \\
\text { 000s }\end{array}$ & $\begin{array}{c}\text { Subject Area 2, } \\
\text { 000s }\end{array}$ & \multicolumn{1}{|c|}{$\begin{array}{c}\text { Subject Area 3, } \\
\text { 000s }\end{array}$} \\
\hline Brazil & 597.2 & 3.2 & Medicine (162,2) I & A/B Science (107,8) II & B/G/M (69,6) III \\
\hline Russia & 709.9 & 5.0 & P/A (246,6) I & Engineering (121,3) III & Chemistry (118,8) II \\
\hline India & $1,001.2$ & 0.91 & Medicine (192,8) II & Engineering (170,4) III & Chemistry (142,1) I \\
\hline China & $3,612.3$ & 2.76 & Engineering (1500) II & P/A (571) III & Material science (558) \\
\hline $\begin{array}{l}\text { South } \\
\text { Africa }\end{array}$ & 167.6 & 3.5 & Medicine (40,3) I & A/B Science (31,5) II & Social science (21.2) \\
\hline
\end{tabular}

Notes: $\mathrm{P} / \mathrm{A}=$ physics/astronomy; $\mathrm{A} / \mathrm{B}=$ animal/biological; $\mathrm{B} / \mathrm{G} / \mathrm{M}=$ biochemistry/genetics/ microbiology. Equivalent ranking on the Web of Science is shown in boldface.

The data shows that the three leading subject areas on Scopus for Brazil, Russia and India are identical, although individual rankings do shift. For China and South Africa important shifts are evident, with the rise of material science and social science to third rank respectively. The emergence of material science in China is less surprising than the leap in rank of social science in South African output, which saw its share of all publications double to $14 \%$ in the period 2007-2012 compared to 1995-1999.

This difference in emphasis revealed between the Web of Science and Scopus is not unexpected: the former began with a strong emphasis on English-language publications in the 
natural sciences and engineering; the latter was established largely to capitalize on the unhappiness this bias elicited among other disciplines and languages [De Bellis, 2009]. The struggle for dominance of the scientific publication marketplace continues.

Perhaps the most important marker of scientific activity is the lead indicator of GERD to GDP. Both India and South Africa have yet to attain the $1 \%$ level; China is now close to $2 \%$. GERD/GDP is an input indicator representing expenditure for research and development (R\&D) with its promise of return to come. Close to half of such expenditure is the labour cost of researchers and support staff. The conventional measure of the size of the research stock is the ratio of full-time equivalent researchers to the labour force. Russia has by far the highest, India the lowest. This points to the lack of an obvious correlation between these two indicators. With the exception of Russia, the ratio of full-time equivalent researchers within the labour force is below the European Union average [OECD, 2015].

Unfortunately GERD data disaggregated by the standard science fields are generally not in the public domain. The little that is published is restricted to specific sectors as shown by the homepages of the UNESCO Institute for Statistics or that of the OECD's Science, Technology and Innovation Directorate.

South Africa is exceptional in publishing such data. These data show that the top three fields by expenditure are engineering and technology (26.5\%), health sciences (17.2\%), and information and communications technology (ICT) (12.8\%), with social sciences ranking fourth at $12.0 \%$. These field expenditures are aggregated across all sectors so it is unsurprising that there is a poor correlation with the intensity of publication outputs that tend to arise mainly from the higher education sector. In higher education one third of expenditure goes toward the social sciences and humanities that gives support to the Scopus finding that the social sciences "matter."

The next topic for consideration is collaboration, for which a proxy measure is scientific co-publication as revealed by search of the Web of Science or Scopus.

\section{Co-publication among the BRICS Countries}

As of 2011 both the Web of Science and Scopus show that some 35\% of scientific articles involved international partners, a rise of $10 \%$ over 15 years [Royal Society, 2011; National Science Board, 2014]. Table 3 presents data on country pair co-publication as captured from the Web of Science.

Table 3: Article Counts and Co-publication, BRICS 2012

\begin{tabular}{|l|c|c|c|c|c|}
\hline & Brazil & Russia & India & China & South Africa \\
\hline Brazil & $\mathbf{3 6 , 1 1 1}$ & $533(2.0)$ & $373(0.8)$ & $623(0.3)$ & $266(2.9)$ \\
\hline Russia & $533(1.5)$ & $\mathbf{2 7 , 3 0 3}$ & $393(0.8)$ & $898(0.5)$ & $237(2.6)$ \\
\hline India & $373(1.0)$ & $393(1.4)$ & $\mathbf{4 6 , 3 4 8}$ & $699(0.4)$ & $262(2.8)$ \\
\hline China & $623(1.7)$ & $898(3.3)$ & $699(1.5)$ & $\mathbf{1 8 3 , 7 6 0}$ & $325(3.5)$ \\
\hline South Africa & $266(0.7)$ & $237(0.9)$ & $262(0.6)$ & $325(0.2)$ & $\mathbf{9 , 2 1 7}$ \\
\hline
\end{tabular}

Note: Bold indicates the total article count. Columns indicate the country-pair co-publication counts; figure in parenthesis is the ratio of this count to article count as a percentage.

Sources: Science Citation Index-Extended, Social Science and Humanities Index, and Arts and Humanities Citation Index. 
South Africa has the highest intensity of BRICS country-pair collaborations, significantly above the median level of $1.4 \%$. Russia is second; China is last. Barely 4,609 (1.5\%) of the 302,739 articles that represent that total scientific production of BRICS members involve a second BRICS country. The reality is that scientific co-publication among the BRICS is low.

Collaboration is a two-way street. The Thomson-Reuters evaluation of Framework Programme 7 outputs suggested that for country-to-country collaboration to be described as "significant" at least $7.5 \%$ of a partner's publications must be concentrated in a field of common interest [Expert Group for the Interim Evaluation of Framework Programme 7, 2010]. By this criterion there is no significant scientific collaboration between any of the BRICS country pairs.

There are, however, much higher levels of co-publication between the BRICS and the United States: Brazil with 5,320 articles or 14.7\%; Russia with 3,020 or 11.1\%; India with 4,270 or 9.2\%; China with 23,829 or $13.0 \%$; and South Africa with 2,250 articles or $24.4 \% .{ }^{1}$ A number of fields of interest to the BRICS exceed the Thomson Reuters $7.5 \%$ level of co-publication concentration. This is overwhelmingly unidirectional: it represents a highly significant channel for knowledge acquisition from the BRICS perspective, but less so for the US or EU.

This is the reality of co-publication; the main site of frontier science is the United States, hence co-publication will pull scientists toward that location. The EU is another major node. Co-publication rates with the EU are $13.6 \%$ for Brazil; $20 \%$ for Russia; $11 \%$ for India; $18.6 \%$ for China and 25\% for South Africa. What Caroline Wagner [2008] termed the "new invisible college of science" has two virtual campuses - the U.S. and the EU. The global community of scientists transacts through the invisible college in spite of, not because of, government policy.

Like its broad economy, South African science is open and international co-publication has risen to nearly $50 \%$ of all locally coauthored articles. Its R\&D expenditure has seen a decline in engineering and technology while research has risen in the health sciences, particularly in the infectious disease area, and the health sciences are acting as a very strong pull for international collaboration [Kahn, 2011]. It is the most prolific of the BRICS in scientific co-publication, and the impact factor of its publications is higher than that of China or Brazil [SAccess, 2011].

One notes the success of South African astronomers and astrophysicists in winning the right to host the bulk of the Square Kilometre Array (SKA) radio telescope that will be the largest scientific instrument yet built [SKA Africa, 2012]. The main array of dishes for high and medium frequencies will be constructed in the interior, with other dishes located in eight African countries. Australia will host the complementary low frequency array. Full SKA operations are expected in 2024 [SKA Organisation, 2012]. O’Neill is wrong; South Africa matters.

\section{To the Future}

STI bilateral agreements are commonplace among the BRICS, and between them and other science-producing countries. These agreements go back many decades and have fostered joint projects and staff exchanges, but the co-publication data is not exactly encouraging. This statement requires some qualification, since certain collaborative activities, such as space and defence, involve intensive STI exchanges that are usually bound by secrecy requirements that preclude open publication.

What about the 2003 IBSA agreement and the subsequent 2010 STI agreement? In 2013 it was noted that "intra-IBSA trade is a clear indication of the potential and success of IBSA as the initial trade target of US $\$ 25$ billion by 2015 is likely to be overshot given the current intra-IBSA trade figure of US\$23 billion. IBSA has also partnered with developing countries, especially

\footnotetext{
1 Russia-Germany co-publication stood at 2,934 articles in the same year.
} 
least-developed countries (LDCs) and post-conflict and reconstruction development (PCRD) countries through the IBSA Facility for Hunger and Poverty Alleviation (IBSA Fund) in development projects that will benefit those countries" [IBSA Dialogue Forum, 2013]. Those responsible for IBSA are thus on record as being satisfied with the "achievement" of the IBSA target, although no counterfactual is available against which the assertion may be tested. Without IBSA the same result would most likely have emerged. The 2010 IBSA STI Agreement seeks to promote the "short-term exchange of scientists, researchers, technical experts and scholars," trilateral workshops and exchange of information, and the "formulation and implementation of trilateral research and development programs" [Government of the Federative Republic of Brazil, Government of the Republic of India and Government of the Republic of South Africa, 2010]. Each signatory is expected to contribute $\$ 1$ million annually to facilitate cooperation. To date there is scant evidence of activity, although it may be too soon to tell. Even so the scale of funding may be too low to attract the attention of top researchers.

The considerations above now allow the appropriateness of the five focal areas of the Cape Town Declaration to be assessed, namely:

- Brazil - climate change and disaster mitigation

- Russia - water resources and pollution treatment

- India - geospatial technology and applications

- China - new and renewable energy, and energy efficiency

- South Africa - astronomy.

A first matter is to make sense of the choices. Clues can be found by assessing the STI "grand challenges" that each country has declared (Brazil describes these as strategic areas). A literature scan indicates the following challenges:

Brazil: biotechnology, nanotechnology, energy, ICT, health, biodiversity and the Amazon, climate change, space science, national security [MST, 2007; Brazil, Ministry of Science and Technology, 2007]

- Russia: energy, nuclear, space science, health, strategic information technology [Meissner, Gokhberg and Sokolov, 2013]

- India: sustainable agriculture, health care, energy, transport and infrastructure, environment, inclusion, space STI [McGrath, Horvath, Baruch et al., 2014]

- China: biotechnology, food security, new energy sources and materials, clean energy vehicles, climate change and environment [McGrath, Horvath, Baruch et al., 2014]

- South Africa: biotechnology, renewable energy, climate change, space STI, poverty alleviation [South Africa, Department of Science and Technology, 2008].

A comparison with Table 2 shows direct overlaps for Brazil, India and South Africa, but less overlap for China and Russia.

The focal areas for Brazil, China and South Africa match the already declared grand challenges or strategic areas. So Brazil has a long tradition of research on Amazonian weather systems and their role in climate change. The country is also experienced in the management of large-scale weather-driven disasters. China, faced with severe pollution in its major cities is now the world leader in photovoltaic energy systems, and is working on clean vehicle technologies. Allocating astronomy to South Africa's aligns with the award of the SKA, and its established work in optical and radio astronomy. China and India are also members of the SKA Organization.

At first sight however there is no clear overlap for Russia or for India. One might speculate that Russia's problems with the pollution of Lake Baikal and the Aral Sea could equip it to lead research in water pollution. India is strong on software development including in geographic information systems, both of which would equip it to work on geospatial technology. 


\section{All at Sea: STI and Geopolitics}

The BRICS is a powerful economic, political and science producing bloc. The O'Neill conjecture retains its merit, but contrary to his view, South Africa - the dominant power in Africa belongs at the main table. The last quarter century saw a shift from the bipolar Cold War to a short period of United States hegemony. A new world disorder is now in the making where various regional superpowers are asserting dormant territorial claims, with uncertain consequences. The Black Sea, South China Sea, Indian Ocean, South Atlantic and Arctic Ocean are all becoming militarized. Old maps are brandished to question boundaries that have blurred with time. John Kenneth Galbraith [1977] might have been optimistic in suggesting that the world was entering an age of uncertainty.

Global science is dealing with its own sea changes. As Hugo Hollanders and Luc Soete [2010] note: "We seem to be on the verge of a structural break in the pattern of knowledge contribution to growth at the level of the global economy. This is also reflected in the arrival on the world scene of large, multinational firms from emerging countries ... [that] are increasingly opting for cross-border mergers and acquisitions to secure technological knowledge overnight." China in particular is poised to become the largest economy and largest producer of scientific publications.

As to intra-BRICS cooperation in science, the publication data attest to this being more rhetoric than reality. The five BRICS countries each engage in much higher levels of cooperation with the centres of science production in the United States and European Union than with one another. Even so, much of this cooperation with the US and EU is unidirectional. South Africa has the highest rate of international co-publication among the five BRICS members.

The Cape Town Declaration on STI was surely based on good intentions, but it has yet to be ratified, and there is no budget on the table. It might well go the same way as the IBSA STI Agreement - good in theory, yet hard to manifest in practice.

The principals of the BRICS Declaration might therefore wish to move beyond rhetoric and factor in the realities of the new invisible college of science. This would require acknowledgement of the central value of the U.S. and EU to global science production as shown in the proliferation of collaboration among the BRICS-U.S.-EU scientific communities. It would make sense for activities in the five proposed focal areas to be open to participants from the U.S., EU and other countries. Including the invisible college will strengthen all participants.

\section{References}

Brazil. Ministry of Science and Technology (2007) Science, technology and innovation for national development: action plan 2007-2010. Summary document. Available at: http://www.access4.eu/_media/Action_Plan_ST_ Brazil.pdf (accessed 5 May 2015).

Cobham A. and A. Sumner (2013) Putting the Gini back in the bottle? "The Palma" as a policy-relevant measure of inequality. 15 March. London: King's College London. Available at: http://www.kcl.ac.uk/aboutkings/ worldwide/initiatives/global/intdev/people/Sumner/Cobham-Sumner-15March2013.pdf (accessed 5 May 2015).

De Bellis N. (2009) Bibliometrics and citation analysis: from the science citation index to cybermetrics. Lanham: Scarecrow Press. Available at: http://elisa.ugm.ac.id/user/archive/download/92386/f2878618868fbea525d0a7 9a8672fa46 (accessed 5 May 2015).

European Commission (2014) European cultural and science diplomacy: exploiting the potential of culture and science in the EU's external relations. Europe as a global actor. H2020-INT-SOCIETY-2015. Brussels: Research and Innovation. Available at: http://ec.europa.eu/research/participants/portal/desktop/en/opportunities/ h2020/topics/1063-int-11-2015.html (accessed 5 May 2015). 
Expert Group for the Interim Evaluation of Framework Programme 7 (2010) Bibliometric anaysis: final report. Leeds UK: Evidence. Thomson Reuters. Available at: http://ec.europa.eu/research/evaluations/pdf/archive/ fp7-evidence-base/experts_analysis/j.\%20adams_-_bibliometric_analysis.pdf (accessed 5 May 2015).

Galbraith J. K. (1977) The age of uncertainty. London: Andre Deutsch.

Glänzel W. (2001) National characteristics in international scientific co-authorship relations. Scientometrics 51(1), pp. 69-115. Available at: 10.1023/A:1010512628145.

Gorodnikova N. (2014) The Russian Federation. In: M. Kahn, L. Martins de Melo and M.G. Pessoa de Matos, eds., Financing innovation. New Delhi: Routledge, pp. 78-133. Available at: http://www.idrc.ca/EN/ Resources/Publications/openebooks/039-8/index.html (accessed 5 May 2015).

Government of the Federative Republic of Brazil, Government of the Republic of India and Government of the Republic of South Africa (2010) Memorandum of understanding on trilateral co-operation in science, technology and innovation. Available at: http://kitplone.itamaraty.gov.br/temas-mais-informacoes/saibamais-ibas/grupos-de-trabalho-e-foros/grupos-de-trabalho/gt-ciencia-e-tecnologia/acordo-em-ciencia-etecnologia/at_download/file (accessed 5 May 2015).

Hollanders H. and L. Soete (2010) The growing role of knowledge in the global economy. In: UNESCO Science Report 2010: the current status of science around the world. Paris: UNESCO, pp. 1-27. Available at: http:// unesdoc.unesco.org/images/0018/001899/189958e.pdf (accessed 5 May 2015).

Hook L. (2013) China smog cuts 5.5 years from average life expectancy. Financial Times, 8 May. Available at: http://www.ft.com/intl/cms/s/0/eed7c0be-e7ca-11e2-9aad-00144feabdc0.html\#axzz3OsvBLDHZ (accessed 5 May 2015).

India-Brazil-South Africa Dialogue Forum (2013) “About IBSA: introduction.” Available at: http://www.ibsatrilateral.org/component/content/category/89-home (accessed 5 May 2015).

Kahn M. (2011) A bibliometric analysis of South Africa's scientific outputs - some trends and implications. South African Journal of Science 107(1/2), pp. 1-6. doi: 10.4102/sajs.v107i1/2.406.

Kuznetsova T. (2013) Russia. In: M. Scerri and H.M.M. Lastres, eds., The Role of the State. New Delhi: Routledge. pp. 80-137. Available at: http://www.idrc.ca/EN/Resources/Publications/openebooks/254-9/ index.html (accessed 5 May 2015).

McGrath C.H., V. Horvath, B. Baruch et al. (2014) The international dimension of research and innovation cooperation addressing the grand challenges in the global context. Santa Monica CA: RAND Corporation. Available at: http://ec.europa.eu/research/innovation-union/pdf/expert-groups/eriab_final_policy_brief_ international_R\&I_cooperation.pdf (accessed 5 May 2015).

Meissner D., L. Gokhberg and A. Sokolov, eds. (2013) Science, technology and innovation policy for the future: potentials and limits of foresight studies. Berlin: Springer Verlag.

Meyer P.A. and M. Nascimento (2014) Some trends in higher education and research in BRICS countries. In: A. Bawa et al., eds., Papers of the Fifth BRICS Academic Forum. Pretoria: Department of International Relations and Cooperation. pp. 117-28. Available at: http://www.dfa.gov.za/department/bricks_fifth_book2014.pdf (accessed 5 May 2015).

National Science Board (2014) Science and engineering indicators 2014. February. Arlington VA: National Science Foundation. Available at: http://www.nsf.gov/statistics/seind14/ (accessed 5 May 2015).

North D.C., J.J. Wallis and B. Weingast (2009) Violence and social orders: a conceptual framework for interpreting recorded human history. Cambridge UK: Cambridge University Press.

Organisation for Economic Co-operation and Development (2015). Main Science and Technology Indicators 2014(2). doi: dx.doi.org/10.1787/msti-v2014-2-en.

Ortiz F. (2014) Brics summits make little progress on science cooperation. SciDev.Net, 21 July. Available at: http:// www.scidev.net/global/cooperation/news/brics-summits-make-little-progress-on-science-cooperation.html (accessed 25 May 2015).

Royal Society (2011) Knowledge, networks and nations: global scientific collaboration in the 21st century. 27 March. London. Available at: https://royalsociety.org/policy/projects/knowledge-networks-nations/report (accessed 5 May 2015). 
SAccess (2011) Report on South African research and innovation capacity. ACCESS4EU - South Africa (Contract number 243851). Available at: http://www.esastap.org.za/download/sa_ri_capacity.pdf (accessed 5 May 2015).

Schwab K., ed. (2014) The global competitiveness report 2014-2015. Davos: World Economic Forum. Available at: http://www3.weforum.org/docs/WEF_GlobalCompetitivenessReport_2014-15.pdf (accessed 5 May 2015).

SKA Africa (2012) SKA site bid outcome. Johannesburg. Available at: http://www.ska.ac.za/about/bid.php (accessed 5 May 2015).

SKA Organisation (2012) The Square Kilometre Array fact sheet. Cheshire UK. Available at: https://www. skatelescope.org/wp-content/uploads/2011/03/SKA_Factsheet_July2012_web_r.pdf (accessed 5 May 2015).

South Africa. Department of Science and Technology (2008) Innovation towards a knowledge-based economy: ten-year plan for South Africa (2008-2018). Available at: http://www.esastap.org.za/download/sa_ten_year_ innovation_plan.pdf (accessed 5 May 2015).

Studwell J. (2013) How Asia works. New York: Grove Press.

Trenin D. (2014) Welcome to Cold War II: this is what it will look like. Foreign Policy, 4 March. Available at: http://foreignpolicy.com/2014/03/04/welcome-to-cold-war-ii (accessed 5 May 2015).

Wagner C. (2008) The new invisible college: science for development. Washington DC: Brookings Institution Press.

World Bank (2010) Innovation Policy in Developing Countries. Washington: World Bank.

Xinhua (2013) Xi Jinping urges deepening reform, innovation-driven development. 5 November. Available at: http://news.xinhuanet.com/english/china/2013-11/05/c_132861473.htm (accessed 5 May 2015). 